\title{
Association of Temporary Environmental Protection Agency Regulation Suspension With Industrial Economic Viability and Local Air Quality in California, United States
}

\section{Emily Chang}

Albemarle High School

Kenneth Zhang ( $\nabla$ kzhang138@gmail.com )

Ancaster High School https://orcid.org/0000-0002-4090-6005

Margaret Paczkowski

Albemarle High School

\section{Sara Kohler}

Waseca High School

Marco Ribeiro

Harvard College

\section{Research}

Keywords: pollution regulations, regulation rollback, particulate matter PM2.5 (PM2.5), employment by industry, state lockdown, coronavirus pandemic, oil refining sector, manufacturing sector

Posted Date: January 28th, 2021

DOI: https://doi.org/10.21203/rs.3.rs-153904/v1

License: (a) (1) This work is licensed under a Creative Commons Attribution 4.0 International License. Read Full License

Version of Record: A version of this preprint was published at Environmental Sciences Europe on April 21st, 2021. See the published version at https://doi.org/10.1186/s12302-021-00489-9. 


\section{Abstract}

\section{Background}

This study seeks to answer two questions about the impacts of the 2020 Environmental Protection Agency's enforcement regulation rollbacks: is this suspension bolstering the economic viability of industries as oil and manufacturing executives claim they will and are these regulations upholding the agency's mission of protecting the environment?

Results

To answer the former question, we utilized employment levels as a method of gauging the economic health of agency-regulated industries. By implementing a machine learning model to predict employment values weekly and a t-test to indicate any significant changes in employment, we found that most industries, including oil, are economically worse off following California's state-issued stay-at-home order and the agency's regulation suspension.

To answer the latter question, we used $\mathrm{PM}_{2.5}$ levels as a metric for local air quality and isolated the impact of regulation rollbacks from the impacts of the state lockdown with treatment-control county pairs. Using the agency's database to collect data and performing a t-test to determine whether treatment-control county pairs experienced a significant change in $\mathrm{PM}_{2.5}$ levels, we found that counties with oil refineries continued to experience the same air pollution levels as before, despite the statewide lockdown.

\section{Conclusions}

From our findings, we can conclude that industries are not witnessing economic growth with these guidelines and state shutdown in place. Additionally, counties with oil refineries could be taking advantage of these rollbacks to continue emitting the same amount of $\mathrm{PM}_{2.5}$, in spite of state lockdowns. For these reasons, we ask international policymakers to reconsider the legislation of similar regulations as these policies do not fulfill their expectations.

\section{Background}

Countries have instituted pollution enforcement regulations to limit the emission of toxic pollutants into the Earth's atmosphere, improving public and environmental health. During the COVID-19 pandemic, some countries, such as South Africa, Brazil, and Australia, have suspended various environmental regulations, potentially endangering environmental health as the pandemic rages across the world. On March 26, 2020, the Environmental Protection Agency (EPA) issued guidelines stating that the agency "...does not expect to seek penalties for noncompliance...that are the result of the COVID-19 pandemic" [15] since the pandemic could constrain the ability to conduct adequate testing [3]. In doing this, the EPA effectively stated that the enforcement of air pollution regulations is temporarily suspended until further notice. Despite its lifting of pollution regulations, the EPA remains committed to protecting public health and improving air quality by reducing pollution [33], indicating that the agency does not foresee that these regulations will negatively affect environmental conditions as the suspension adheres to the agency's mission statement. These guidelines place regulated economic sectors on an honor system, requiring industries to keep records of noncompliance but not 
requiring them to release these records to the public or report them to the EPA. The agency's actions are supported by executives of top oil companies who have said that "...tighter regulations on emissions of fine soot would harm their economic viability." [10]

However, these statements have drawn skepticism and raised significant concerns. A study by Giannakis et al. has highlighted the need for better air quality policies to reduce air pollution and negative health impacts in Europe [20]. In the US, certain regions are more exposed to the effects of increased pollution levels. Scholars have found that in the Appalachian region, an area exploited by industries that establish and abandon hazardous facilities, residents face severe environmental risks [30].

Most concerning are the links between pollution levels, diseases, and mortality. Before the coronavirus disease 2019 (COVID-19) outbreak, large swaths of the global population were at risk for dying from an air pollutantrelated disease with the World Health Organization (WHO) estimating in 2016 that nearly 3 million people die each year from air pollution-related diseases [34]. This statistic is expected to increase as exposure to fine particulate matter $\left(\mathrm{PM}_{2.5}\right)$, a complex mixture of small particles and liquid droplets with aerodynamic diameter $\leq 2.5 \mu \mathrm{m}$ in the atmosphere [38], leads to a higher risk of dying from COVID-19. A Harvard study conducted by Wu et al. indicates that residents living in areas with high levels of $\mathrm{PM}_{2.5}$ are $8 \%$ more likely to die from COVID-19 [36], indicating that the deregulation of air pollutant emissions could intensify the growing public health crisis in the era of the COVID-19 pandemic.

Nationwide lockdowns have led to the decline of air pollutants during the COVID-19 pandemic. According to 2020 satellite data, major cities in Europe have witnessed significant reductions in nitrogen dioxide concentrations throughout middle to late March [18]. Similar results could be found in China, which experienced a $10-30 \%$ decrease in nitrogen dioxide concentrations [26].

While nationwide quarantines appear to limit pollutant emissions, pollutant emissions have been making a comeback. Analysts have witnessed that while fossil fuel consumption may have bottomed out earlier in the year, coal consumption returned to normal levels by March 30, 2020. On the same note, nitrogen dioxide levels have also returned to normal levels with provincial governments approving a surge of new coal power plant projects, indicating that pollution levels are bound to rise as industries manufacture more to make up for lost time and thus, release even more pollutants [25]. Given the current conditions of this pandemic era, the lack of regulations that could limit the emissions of pollutants ultimately puts the health of our environment and public health at risk.

The EPA claims the new guidelines will lead to increased economic viability for the manufacturing and oil sectors and will continue to uplift the EPA's mission of protecting environmental health. However, there remains a paucity of information regarding the impact the EPA regulation suspension might have on air pollution levels and the economic viability of industries. If the EPA's justifications prove to be invalid, heightened levels of air pollution could strain our nation's healthcare system with increased COVID-19 cases without promoting the economic recovery some industries expect. We aim to analyze whether the EPA's claims are indeed valid and draw a thorough analysis to help federal policymakers at the agency devise effective air pollution control programs so that these detrimental scenarios might be prevented.

\section{Methods}


Initially, to detail the circumstances of the economic shutdown created from statewide stay-at-home orders, we looked into gross state product (GSP) [2], a common measure of the size of the economy and growth rate. However, GSP is measured over the course of three months, a frequency that was too low. Consequently, we turned to economic proxies that were measured on a more frequent basis, including national oil consumption data [13], state oil production data [6], federal unemployment levels [35], state unemployment levels [14], and state employment levels by industry [14]. We focused on the state of California since it has the largest population and rich data.

To determine whether the rollbacks were associated with increased economic viability for economic sectors, we collected employment data on several treatment industries, or industries that we assumed the EPA regulations could impact according to the agency's page on regulatory and compliance assistance by sector [17]. Here, employment serves as a proxy for economic health for an industry as Okun's law states that unemployment is inversely correlated with Gross Domestic Product (GDP), an indicator of economic health [19]. Employment values from the treatment industries: Oil \& Gas Extraction; Mining, except Oil \& Gas; Paper Manufacturing; Wood Product Manufacturing; Construction; and Automotive Parts, were collected from the California Employment Department [14]. Using unemployment data provided by the United States Department of Labor [35], we subtracted continued unemployment claims from covered employment data to determine total employed persons within the state of California. To compute our weekly employment values for control industries, we summed the employment values from the treatment industries and subtracted them from total employed persons.

Predicting NaN Values Using K-Nearest Neighbors Imputer

We only had access to monthly local unemployment data but needed them to be recorded weekly to conduct an effective statistical analysis. To predict weekly unemployment values, machine learning engineers must attempt to eliminate as many noise-causing factors such as Not a Number ( $\mathrm{NaN}$ ) values, or missing values. To eliminate these factors, we needed to find an algorithm that would ignore the NaN values or substitute accurate predictions of the NaN values to provide a sufficient amount of values.

To substitute the NaN positions with accurate predictions of weekly employment values, we used different algorithms to predict those values dependent on the shape and form of the data. The monthly data that was provided was filled with data points at different checkpoints meaning that the data could be predicted by taking samples of the data. The KNNImputer algorithm was the best for filling in these values as it takes samples of missing values and the NaN values are imputed using the mean values from the nearest neighbors found in the training set. From this, we can insert the imputed values into the NaN positions respectively, predicting future unemployment values.

Predicting Future Employment Values for Each Industry

The employment by industry data provided by the California Employment Department [14] was sparse and insufficient for predicting future values. Due to the paucity of data points provided, we had to determine an algorithm to predict future values. We initially believed that linear modeling algorithms would fit the data best due to the ability of linear algorithms to predict scarce data. Specifically, the ability of the Bayesian Ridge 
Regression (BRR) algorithm was favored as its natural mechanism's ability to survive in insufficient or abysmally distributed data. However, the algorithm is optimized more in some of the industry data samples than others. Due to this randomized nature, we would have had to use different algorithms to predict future values of industry data samples, introducing a level of bias in the prediction of future values based on data samples of different industries. We had to find an algorithm that was mathematically flexible enough but could also be altered depending on the sparseness of the data to best fit the data sample of a specific treatment industry.

To eradicate bias from the models, we needed to find a regression analysis algorithm that could model the relationship between the ' $x$ ' and ' $y$ ' using the powers of a function. Polynomials are best suited for this scenario, as they are expressions that contain indeterminates and coefficients that can be adjusted to fit data samples the best and produce the most accurate predictions. To do this, we selected polynomial regression analysis, a configuration of regression analysis that is designed to model the relationship between ' $x$ ' and ' $y$ ' variables to the "nth" degree of a polynomial. This allows the function to adjust its coefficients to precisely fit the sample of data for a specific treatment industry. Computationally, we utilized the NumPy Python 3.7.7 Package to fit these polynomial functions to efficiently and sufficiently model the data.

To achieve precise modeling of the polynomial regression line that would later be fitted with the treatment industry's data, we used the Python programming language to build models based on the data that was inputted into the ' $x$ ' and ' $y$ ' variables. We proceeded to initialize two variables; one that would represent the range of the ' $x$ ' variables, and another variable that would represent the power of variables. The polynomial regression line was manipulated to allow us to control the power and smoothness of the polynomial regression line. Manipulative modifications did not affect the results.

Managing Air Quality Data

To assess local air quality, the pollutant analyzed was $\mathrm{PM}_{2.5}$ as it fluctuates and can quickly react to changes in the local environment [21, 22]. Data from 2009 to 2020 were collected from the EPA's Outdoor Air Quality Index (AQI) [16]. Data was filtered to contain only measurements from California as some of the state's counties were known for having high levels of long and short term particle and ozone pollution before COVID-19 [1]. Parts of the study utilized daily mean $\mathrm{PM}_{2.5}$ concentration levels for specific counties while others averaged these values weekly.

Selecting Treatment-Control County Pairs

The aim of this study was to investigate the impacts of the rollbacks rather than the impacts of the state shutdown. We assumed the shutdown applied to all counties equally, but the rollbacks would not, as each county specializes in a different economic sector that may or may not be regulated by EPA

guidelines.Consequently, we identified an industry that would be impacted by the new EPA guidelines. From here we could then identify two counties: a treatment county, which had the industry, and a control county that was similar in every way to the treatment, except that it did not have the impacted industry.

The fine print of the EPA guidelines suggests that the enforcement of pollution regulations is relaxed for all regulated entities, or economic sectors: "The consequences of the pandemic may constrain the ability of regulated entities to perform routine compliance monitoring, integrity testing, sampling, laboratory analysis, training, and reporting or certification [and]...may affect the ability of an operation to meet enforceable 
limitations on air emissions" [3]. Following the rollback of the enforcement of pollution regulations, the EPA released new guidelines that were designed with oil industries in mind [23] as the EPA advocated to "ease control on coal plants' toxic ash and loosen restrictions on mercury emissions" [32], establishing legislation that benefits fossil fuel industries. The agency established the new guidelines three days after executives from the American Petroleum Institute (API) petitioned the EPA to roll back "non-essential compliance obligations" [4]. Additionally, the EPA rollbacks meet the requests stated in the API petition, including (but not limited to) wet signature requirements, potential delay to project permits, deferred permit renewal applications, and potential to miss certifying laboratory equipment [24].

However, the manufacturing sector and oil industry are linked as the finished products of oil industries are the inputs for manufacturing sectors to convert the raw materials in finished goods [12]. The manufacturing sector is also an industry listed as being regulated by the EPA, indicating that manufacturing sectors could be impacted by the regulations.

We created two pairs of treatment-control pairs: one for oil refineries and one for the manufacturing sector. Using oil refinery data [29], population data [5], and manufacturing establishment data [7], we identified two counties in California, Contra Costa and Sacramento, that have similar population densities, manufacturing establishments densities, and general climates. However, Contra Costa has a major oil industry as it has four oil refineries which produce a significant amount of oil each day (Fig. 2b), while Sacramento does not. We identified two other counties, Napa and Sutter, which have similar population densities and general climates. Napa, according to the 2010 United States Census Bureau, ranked in the top 30 Californian Manufacturing Cities, while Sutter did not, indicating that the manufacturing sector in Sutter appears to not be significant using industrial data from 2010.

Geographic locations of Contra Costa and Sacramento (left) and Napa and Sutter (right)

Economic overview of select California counties. Using data from the United States 2010 Census Bureau and journal Oil, we graphed a. main manufacturing sectors for 30 Californian counties, b. output of major Californian oil refineries, c. population density, and $\mathbf{d}$. manufacturing density

\section{Statistical Analysis}

To determine association, we programmed in $\mathrm{R}$ to conduct $\mathrm{t}$-tests. We split the data into a pre-shutdown and prerollback time series, which was composed of weekly and daily data before March 31, 2020, and a post-shutdown and post-rollback time series, which was composed of data after April 1, 2020. A two-sided paired t-test was used when comparing the treatment to control while a two-sided unpaired t-test was used when comparing preshutdown and pre-rollback to post-shutdown and post-rollback data.

\section{Results}

Measuring Economic Activity

Comparison of weekly $\mathrm{PM}_{2.5}$ levels (top) and local unemployment levels (bottom) in Fresno, California in March 2020 
Since GDP is recorded over three months and we wanted more frequent data, we sought an economic proxy that could act as a metric of economic activity concerning $\mathrm{PM}_{2.5}$ levels. After utilizing K-Nearest Neighbors Imputer to predict unemployment levels by county, we plotted weekly mean $\mathrm{PM}_{2.5}$ values against weekly unemployment values. The month of March experienced a significant change in unemployment and pollution with a $45 \%$ increase in unemployment and a 74\% decrease in $\mathrm{PM}_{2.5}$ for the county of Fresno (Fig. 3). The results in Fig. 3 indicate an inverse relationship between unemployment and $\mathrm{PM}_{2.5}$ for the month of March.

Table 1

Correlation coefficients showing the statistical relationship between weekly $\mathrm{PM}_{2.5}$ and local unemployment levels

\begin{tabular}{|ll|}
\hline County & Correlation Coefficient \\
\hline Contra Costa & -0.4435 \\
\hline Napa & -0.60851 \\
\hline Sacramento & -0.66302 \\
\hline Sutter & -0.68531 \\
\hline
\end{tabular}

The relationship can also be quantitatively established by running a correlation coefficient test on weekly pollution and unemployment data from February 16, 2020, to May 31, 2020. As shown in Table 1, the negative correlation coefficient values indicate that there is an inverse relationship between these two variables with some counties, such as Napa, Sacramento, and Sutter, exhibiting a stronger inverse relationship between unemployment and pollution than other counties, such as Contra Costa.

Evaluating the Economic Viability of Certain Industries

Total employed persons for treatment and control industries. Using an algorithm to predict an industry's total employment, graphs for total employed persons for a. all control, b. automotive, c. construction, d. mining, e. oil, f. paper, and g. wood industries were created

After affirming that unemployment could be a measure of economic activity on a county level, we evaluated the economic health of several state industries using employment data. We developed a model to predict total employed persons for specific industries weekly using monthly employment data provided by the California Employment Department [14], producing a richer data set. These values were then plotted in Fig. 4, comparing the employment values of treatment industries, or industries that could be affected by the rollbacks, to those of control industries, or industries that could be unaffected by rollbacks.

Data was then split into two categories: pre-shutdown and rollback, or weekly employment data that occurred before March 31, 2020, and post-shutdown and rollback, or weekly employment data that occurred after April 1, 2020. California issued a statewide stay-at-home order on March 19, 2020, and the EPA rolled out new guidelines on March 26, 2020.

Two two-sided paired t-tests, one using pre-shutdown and pre-rollback data and the other using post-shutdown and post-rollback data, were conducted using the employment values of a treatment industry and those of 
control industries. For these two t-tests, our null hypothesis stated that total employed persons for treatment and control industries were not statistically different before or after COVID and rollbacks. Our alternative hypothesis stated the opposite: the employment values for treatment and control industries were statistically significant before and after COVID and rollbacks. Both paired t-tests produced statistically significant values $\left(p<5 \otimes 10^{-11}\right)$ for each of the 6 treatment industries, possibly indicating that the employed persons of treatment industries are indeed different from those of control industries before and after the state shutdown and EPA rollback.

A two-sided unpaired t-test was conducted comparing pre-shutdown and pre-rollback employment data to postshutdown and post-rollback data for the control industries and each of the 6 treatment industries. The null hypothesis stated that there was no statistically significant difference in an industry's employed persons after shutdown and rollbacks, while the alternative hypothesis indicated that there was a statistically significant difference in an industry's employment values after shutdown and rollbacks. As shown in Table 2, most industries, including the control industries, turned up statistically significant $(p<0.05)$. On the other hand, other industries, such as Construction and Wood Manufacturing, produced p-values that were not statistically significant $(p>0.05)$ (Table 2).

Table 2

\begin{tabular}{|ll|}
\multicolumn{2}{|c|}{$\begin{array}{c}\text { P-values of employed persons } \\
\text { before and after shutdown } \\
\text { and rollbacks (two-sided } \\
\text { unpaired t-test) }\end{array}$} \\
\hline Industry & P-value \\
\hline Control & 0.0001803 \\
Automotive & 0.0001606 \\
\hline Construction & 0.319 \\
\hline Mining & 0.003052 \\
\hline Oil & 0.009941 \\
\hline Paper & 0.0001068 \\
\hline Wood & 0.4355 \\
\hline
\end{tabular}

Evaluating Air Pollution in Treatment-Control Pairs

We collected daily $\mathrm{PM}_{2.5}$ data [16] from the oil refinery treatment-control pair (i.e. Contra Costa and Sacramento) and manufacturing treatment-control pair (i.e. Napa and Sutter). This data was averaged weekly and later split up into pre-shutdown and pre-rollback data, 2019 spring or early 2020 data, and post-shutdown and postrollback data, data after April 1, 2020. 
Table 3

P-values of pre-shutdown and pre-rollback $\mathrm{PM}_{2.5}$ values for treatment-control counties (two-sided paired t-test)

\begin{tabular}{|lll|}
\hline Frequency & \multicolumn{2}{l|}{ Treatment-Control Pair } \\
\cline { 2 - 3 } & Contra Costa - Sacramento & Napa \\
& & - Sutter \\
\hline Weekly & 0.003271 & 0.7945 \\
\hline Daily & $2.60 \mathrm{E}-07$ & 0.621 \\
\hline
\end{tabular}

$\mathrm{PM}_{2.5}$ values before March 31, 2019, for a treatment and control county were used as pre-shutdown and prerollback data and inputted into a t-test. Weekly and daily data samples were used

Weekly spring and summer $\mathrm{PM}_{2.5}$ levels from 2019 were used as pre-shutdown and pre-rollback data. Preshutdown and rollback data for a treatment county were compared to those of its control county in a two-sided paired t-test in R. The null hypothesis stated that the type of industry present in the treatment county was not associated with $\mathrm{PM}_{2.5}$ levels. The alternative hypothesis stated that the presence of the industry in the treatment county was associated with $\mathrm{PM}_{2.5}$ levels. As shown in Table 3, the treatment-control pair for oil industries produced statistically significant values using weekly and daily data $(p<0.05)$. On the other hand, the manufacturing treatment-control pair did not test statistically significant $(p>0.05)$ (Table 3$)$.

Table 4

P-values of pre- and post-shutdown and rollback $\mathrm{PM}_{2.5}$ levels (twosided unpaired t-test)

\begin{tabular}{|c|c|c|c|c|}
\hline \multirow[t]{2}{*}{ Frequency } & \multicolumn{4}{|l|}{ County } \\
\hline & Contra Costa & Sacramento & Napa & Sutter \\
\hline Weekly & 0.3349 & 0.003492 & 0.1401 & 0.7499 \\
\hline Daily & 0.1459 & 1.48E-08 & 0.01304 & 0.7815 \\
\hline
\end{tabular}

Data from April 1, 2019, to June 30, 2019, was used as pre-shutdown and pre-rollback data. Data from April 1, 2020, to June 30,2020 , was used as post-shutdown and post-rollback data. Pre- and post-shutdown and rollback were compared for each county in a t-test. Daily and weekly data samples were used.

Weekly spring and summer $\mathrm{PM}_{2.5}$ data from 2019 and 2020 were used as pre- and post-shutdown and rollback data, respectively. Pre-shutdown and pre-rollback data were compared to post-shutdown and post-rollback data for each county in an unpaired two-sided t-test. The null hypothesis stated that a county's $\mathrm{PM}_{2.5}$ levels did not change after the state shutdown and EPA rollbacks. The alternative hypothesis stated that $\mathrm{PM}_{2.5}$ levels did change after the state shutdown and EPA rollbacks. As shown in Table 4, Sacramento consistently turned up statistically significant $(p<0.05)$ while Contra Costa did not $(p>0.05)$. 
Table 5

P-values of post-shutdown and post-rollback $\mathrm{PM}_{2.5}$ data for treatment-control pairs (two-sided paired t-test)

\begin{tabular}{|lll|}
\hline Frequency & \multicolumn{2}{c|}{ Treatment-control Pair } \\
\cline { 2 - 3 } & Contra Costa - Sacramento & Napa \\
& & - Sutter \\
\hline Weekly & $6.17 \mathrm{E}-07$ & 0.08321 \\
\hline Daily & $2.20 \mathrm{E}-16$ & 0.0009928 \\
\hline
\end{tabular}

Data from April 1, 2020, to June 30, 2020, were used as post-shutdown and post-rollback data for each treatment and control county and were inputted into a t-test. Daily and weekly samples were used

Spring and summer $\mathrm{PM}_{2.5}$ data 2020 was used as post-shutdown and post-rollback data. Post-shutdown and post-rollback data for the treatment and control county were compared in a two-sided paired t-test. The null hypothesis stated that the $\mathrm{PM}_{2.5}$ levels from the treatment county were not statistically significant to those of its control county. The alternative hypothesis stated that the $\mathrm{PM}_{2.5}$ levels of the treatment county were statistically significant to those of its control county. As shown in Table 5, the oil refinery treatment-control pair produced statistically significant $p$-values $(p<0.05)$ using weekly and daily data (Table 5$)$. However, the manufacturing treatment-control pair produced $p$-values that were not statistically significant $(p>0.05)$ (Table 5$)$.

Weekly $\mathrm{PM}_{2.5}$ Levels Across all 4 counties from January 2020 to June 2020

In Fig. 5, we noticed that the control of the oil industry treatment-control pair (Sacramento) had higher $\mathrm{PM}_{2.5}$ levels than its treatment (Contra Costa) before the state shutdown and EPA rollbacks. However, we noticed that this behaviour is switched after the state shutdown and EPA rollbacks: Contra Costa now has higher levels of $\mathrm{PM}_{2.5}$ than Sacramento. This behaviour is not the same for the manufacturing treatment-control group. Sutter has higher $\mathrm{PM}_{2.5}$ levels than Napa but this difference is not as consistent after shutdown and rollbacks.

Table 6

P-values of $\mathrm{PM}_{2.5}$ differences before and after shutdown and rollbacks (two-sided paired t-test)

\begin{tabular}{|ll|}
\hline Treatment-Control Pair & p-value \\
\hline Contra Costa-Sacramento & 0.0002155 \\
\hline Napa-Sutter & 0.04157 \\
\hline
\end{tabular}

From January 1, 2020, to June 30, 2020, a control county's $\mathrm{PM}_{2.5}$ levels were subtracted from a treatment county's $\mathrm{PM}_{2.5}$ levels. Data before March 31, 2020, became pre-shutdown and pre-rollback data while data after April 1, 2020, became post-shutdown and post-rollback data. For each treatment-control pair, pre- and postshutdown and rollback data were inputted into a t-test. 
To determine whether the differences in $\mathrm{PM}_{2.5}$ levels for the treatment and control county before and after shutdown and rollbacks were statistically significant, we subtracted the $\mathrm{PM}_{2.5}$ values of a control county from those of its treatment county from January 1, 2020, to June 30, 2020. Data from January 1, 2020, to March 31, 2020, acted as pre-shutdown and pre-rollback data, while data from April 1, 2020, to June 31, 2020, acted as post-shutdown and post-rollback data. These differences were then inputted into an unpaired two-sided t-test. The null hypothesis states that the difference between the treatment-control pair before and after the state shutdown and EPA rollbacks were not statistically significant, whereas the alternative hypothesis states that the differences after the state shutdown and EPA rollbacks were statistically significant. As shown in Table 6, the oil industry treatment-control pair has a higher statistically significant $p$-value $(p<0.0001)$ than the $p$-value for the manufacturing treatment-control pair.

\section{Discussion}

Our study seeks to provide an objective analysis of the impacts EPA regulation rollbacks could have on the economic viability of certain industries and local air quality. A correlation coefficient test conducted on total unemployed persons and local $\mathrm{PM}_{2.5}$ levels revealed that total unemployment numbers and local air quality were inversely related (Table 1). We used employment as a metric for gauging the economic health of an industry and $\mathrm{PM}_{2.5}$ levels as a standard for measuring local air quality.

When determining whether the EPA's enforcement rollbacks were bolstering the economic viability of certain industries, we found that the association between the EPA rollbacks and the economic health of a regulated industry varied significantly - some industries are financially worse off while others are better off after rollbacks. We classified employment data before March 31, 2020 as pre-shutdown and pre-rollback data while data after April 1, 2020 was classified as post-shutdown and post-rollback data since rollbacks and shutdown occurred approximately at the same time. When pre- and post-shutdown and rollback data for each industry were inputted into a two-sided unpaired t-test, p-values for the control, automotive, mining, oil, and paper industries were statistically significant $(p<0.01)$ (Table 2). Because of the t-test conducted in Table 2 , we can be confident that the employment values for these industries after the shutdown and rollbacks are not similar to those before the shutdown and rollbacks. For many of these industries, such as automotive, oil, and paper, current employment values have not returned to pre-shutdown and pre-rollback levels (Fig. 4). However, the mining industry's employment values have returned and surpassed pre-shutdown and pre-rollback levels, indicating that its economic viability is currently better than what it had been at the beginning of the year. On the other hand, other industries, such as the construction and wood industries, produced p-values that were not statistically significant $(p>0.05)$ (Table 2$)$. These statistically not significant $p$-values could be associated with the workforce stability of these industries. For instance, industries like construction tend to employ temporary workers which made up $15.5 \%$ of employees in the construction industry in 2014 [8]. Doing so made it easier for companies to quickly adjust their labor [8], potentially making it easier to quickly rebuild during a state shutdown.

To create a richer data set, we predicted employment values on a weekly basis for regulated industries. A polynomial regression algorithm fitted a quartic function to each of the treatment industry's employment values. Any other type of function would result in inaccurate predictions. While Table 7 indicates that the polynomial regression algorithm could accurately predict data, additional data would allow the algorithm to identify stronger correlations with the data and thus improve the accuracy of the algorithm.

Page $11 / 23$ 
Table 7

Polynomial regression algorithm accuracies for the six treatment industries

\begin{tabular}{|ll|}
\hline Industry & Model Accuracy \\
\hline Automotive & $98.521 \%$ \\
\hline Construction & $90.226 \%$ \\
\hline Mining & $93.399 \%$ \\
\hline Oil & $99.645 \%$ \\
\hline PaperManufacturing & $97.526 \%$ \\
\hline Wood Manufacturing & $89.573 \%$ \\
\hline
\end{tabular}

Our study also sought to answer an environmental question: were these rollbacks upholding the agency's mission of protecting the environment, or more specifically, not negatively impacting the environment? To answer this question, the focus of the study shifted from industry-based to location-based.

To determine whether certain industries were associated with $\mathrm{PM}_{2.5}$ levels, we compared 2019 spring and summer data for treatment-control pairs in a two-sided paired t-test and obtained statistically significant $\mathrm{p}$ values for the Contra Costa-Sacramento pair $(p<0.005)$ but not for the Napa-Sutter pair $(p>0.05)($ Table 3), indicating that the presence of an oil refinery could be associated with $\mathrm{PM}_{2.5}$ levels. This finding is supported by a study conducted by Zhang et al. who found that excluding meteorological factors, the production of natural gas, industrial boilers, ore, tractors, nuclear power, and locomotives have the highest association with $\mathrm{PM}_{2.5}$ concentration in China [37]. Zhang et al.'s report also suggests that the presence of a manufacturing sector could be associated with $\mathrm{PM}_{2.5}$ levels. Using data from DataUSA [9], Table 8 indicates that Napa and Sutter's economies were not as well matched as we initially thought, thus producing the statistically not significant pvalues $(p>0.05)$ in Table 3. Consequently, we cannot associate the presence of a manufacturing section with $\mathrm{PM}_{2.5}$ levels.

Table 8

Overview of concentration of occupations in select Californian counties

\begin{tabular}{|lllll|}
\hline Occupation & Contra Costa & Sacramento & Napa & Sutter \\
\hline Agriculture, forestry, fishing, hunting & $0.50 \%$ & $0.60 \%$ & $6.40 \%$ & $5.20 \%$ \\
\hline Mining, quarrying, oil and gas extraction & $0.30 \%$ & $0.00 \%$ & $0.30 \%$ & $2.00 \%$ \\
\hline Construction & $6.90 \%$ & $5.70 \%$ & $5.60 \%$ & $13.30 \%$ \\
\hline Manufacturing & $6.90 \%$ & $4.90 \%$ & $11.70 \%$ & $10.00 \%$ \\
\hline Wholesale trade & $2.40 \%$ & $2.50 \%$ & $2.90 \%$ & $1.00 \%$ \\
\hline Retail trade & $10.80 \%$ & $10.40 \%$ & $11.10 \%$ & $9.70 \%$ \\
\hline Transportation and warehousing & $3.80 \%$ & $3.80 \%$ & $1.90 \%$ & $2.00 \%$ \\
\hline Utilities & $1.10 \%$ & $1.00 \%$ & $0.60 \%$ & $3.00 \%$ \\
\hline
\end{tabular}


To determine whether $\mathrm{PM}_{2.5}$ levels were significantly different after the shutdown and rollbacks, spring 2019 data was compared to spring 2020 daily data for each county, producing p-values that were statistically significant for Sacramento $\left(p<0.01\right.$ ) (Table 4), potentially indicating that the $\mathrm{PM}_{2.5}$ levels after the shutdown and rollbacks were different from those before due to the state lockdown. P-values for Contra Costa and Sutter were not statistically significant $(p>0.05)$ (Table 4$)$, indicating that $\mathrm{PM}_{2.5}$ values after the shutdown and rollbacks were not statistically different than those before. Contra Costa has a significant oil industry while its control county does not. These oil refineries could be taking advantage of the present EPA regulations, causing the same amount of pollution levels to be produced after the shutdown and rollbacks. Napa tested inconclusive; the use of a weekly sample did not produce a statistically significant $p$-value $(p>0.05)$, whereas a daily sample did $(p<0.05)$ (Table 4). A daily data sample might be richer and noisier than a weekly data sample, causing this variation.

To determine whether a treatment and its control county's $\mathrm{PM}_{2.5}$ levels were statistically different following the state shutdown and EPA rollbacks, spring 2020 data for each of the treatment-control pairs were inputted into a two-sided paired t-test. The Napa-Sutter pair tested inconclusive as weekly and daily data samples produced different $\mathrm{p}$-values. The Contra Costa-Sacramento pair produced a statistically significant $\mathrm{p}$-value $\left(p<1.0 \otimes 10^{-6}\right)$ (Table 5). While Contra Costa and Sacramento had similar economies, Contra Costa has a higher concentration of fossil fuel industries than Sacramento (Table 8). These oil refineries in Contra Costa could have remained in operation during the pandemic and continued emitting $\mathrm{PM}_{2.5}$, causing the statistical difference in pollution levels between Contra Costa and its control county.

To investigate the relationships seen in Fig. 5, the differences in pollution between the treatment-control pairs before and after the lockdown and rollbacks were compared in a two-sided unpaired t-test. Both treatmentcontrol pairs tested statistically significant $(p<0.05)$ (Table 6$)$. Since all four counties were influenced by COVID but experienced varying degrees of impact from rollbacks as a result of their economies, certain industries, particularly oil refineries, could take advantage of the EPA suspension to continue producing the same amount of pollution well after the state lockdown and rollbacks.

The results produced by the t-tests are not due to seasonality as spring and summer 2019 data was compared to spring and summer 2020 data. The behavior of $\mathrm{PM}_{2.5}$ levels in 2020 do not always mirror historical pollution data. In Fig. 6, some counties, such as Napa, continued to have higher pollution levels in 2020 than in the past decade, despite California's state lockdown.

Difference between average 2009-2019 PM $_{2.5}$ levels and 2020 PM $_{2.5}$ levels for a Contra Costa, b Sacramento, c Napa, and $\mathbf{d}$ Sutter

While we tried to eliminate as many hidden variables as possible by making the treatment and control counties similar to one another, our choices were not perfect. For instance, Contra Costa and Sacramento might experience the same general climate but have varying microclimates [31], which could then influence pollution levels [28]. While Table 8 validates our conclusion that Contra Costa has an oil industry and Sacramento lacks one, Napa and Sutter devoted differing amounts of their population to fossil fuel industries and construction, industries that are well known for exacerbating pollution levels [11]. According to Table 8, Sutter's manufacturing sector is almost equal to that of Napa's, meaning that its manufacturing sector was not as insignificant as we initially thought.

Page $13 / 23$ 
We can conclude that Contra Costa and Sacramento are a better match than Napa and Sutter. Based on Table 4, we can conclude that oil industries could be producing the same amount of pollution levels before and after the state shutdown, potentially as a result of these regulations. While we do not have sufficient evidence to say the same for manufacturing sectors, it is important to note the environmental repercussions of what could happen when the state lockdowns are lifted and industries, such as oil refineries, can return to normal levels of activity without the presence of regulations to limit emissions. Generally speaking, the results from Fig. 4 and Table 2 indicate that most industries are doing worse following the shutdown and rollbacks. A qualitative analysis of Fig. 4 indicates that the rollbacks might not be associated with increased economic viability for all industries, even for the oil industry which championed the rollbacks. To quantitatively ascertain this assertion, a paired ttest could be conducted and look into the differences between the employment levels of a treatment industry and those of the control industries. The null hypothesis for this procedure must take into account the differences between treatment and control under normal circumstances. The null hypothesis would be different for each industry and would have to be extrapolated from the average difference in performance between each one of the industries and the treatment.

While the regulation suspension was lifted in August 2020, we advise against the establishment of similar legislation. The regulatory suspension in America was not an isolated incident as many countries around the world have deregulated many environmental policies. Seeing that these guidelines neither meet the economic expectations of oil and manufacturing executives nor uphold the EPA's mission of protecting the health of our environment, we ask policymakers to not suspend environmental regulations.

\section{Conclusion}

The statistical analysis of employment levels does not indicate a clear association between the EPA rollback regulations and the improved economic viability of certain industries during the COVID-19 pandemic.

Additionally, a statistical analysis of $\mathrm{PM}_{2.5}$ levels across certain counties indicates that certain counties experienced significant changes in pollution levels after state lockdowns and rollbacks while other countries possessing certain pollution-associated industries, namely oil refineries, are experiencing pollution levels similar to those of 2019 .

While levels of economic activity will continue to remain below average until California's state lockdown is completely lifted, it is important to note the environmental and public health repercussions of what might result from these regulations. If pollution emissions are not checked, residents face the risk of a polluted environment, endangering their health in a public health crisis, aggravated by COVID.

During the age of the COVID-19 pandemic, most EPA-regulated sectors are economically worse off. In a time when financially aiding large and small businesses is considered a paramount priority, these guidelines fail to satisfy the expectation oil and manufacturing executives have proposed: additional financial assistance in a time of economic recession. Industries who have backed these regulations continue to face declining economic health as seen in decreasing employment levels.

This study's statistical analysis of employment levels by industry and $\mathrm{PM}_{2.5}$ levels by county provides the EPA's specialists, United States' legislators, and international policymakers with the needed information for designing 
effective pollution and industry regulations. This study highlights the need for the reconsideration of similar regulations. Further research could reinforce the environmental and economic findings of this study.

\section{Abbreviations}

API

American Petroleum Institute

AQI

Air Quality Index

BRR

Bayesian Ridge Regression

COVID-19

Coronavirus Disease 2019

EPA

Environmental Protection Agency

GDP

Gross Domestic Product

GSP

Gross State Product

KNN

K-Nearest Neighbors

$\mathrm{PM}_{2.5}$

Fine Particulate Matter 2.5

$\mathrm{NaN}$

Not a Number

WHO

World Health Organization

\section{Declarations}

\section{Ethics approval and consent to participate}

Not applicable

\section{Consent for publication}

Not applicable

\section{Availability of data and materials}

The dataset supporting the conclusions of this article is available in the Environmental Protection Agency's Outdoor Air Quality Database, https://www.epa.gov/outdoor-air-quality-data/download-daily-data. Other datasets supporting the conclusions of this article are included within the article and its additional files. 


\section{Competing interests}

The authors declare that they have no competing interests.

\section{Funding}

Not applicable

\section{Author's Contributions}

EC performed statistical analysis on air pollution data and employment data, drafted the code for many of the paper's visualizations, and was a major contributor in writing the manuscript. KZ programmed machine learning algorithms in Python and R to predict employment levels on a weekly basis and was a major contributor in writing the manuscript. SK formatted many of the paper's figures. MP was a major contributor in writing the paper. MR aided in the analysis of environmental and economic data, the layout of the study's design, and made substantial revisions to the manuscript. All authors read and approved the final manuscript.

\section{Acknowledgments}

We acknowledge the following persons for their role in this paper: Dr. Christopher Taylor, Dr. Arthur Smalls, Dr. Jon Goodall, Dr. Kathleen Segerson, Dr. Joni Seager, Kripa Kirshnan, Karthik Shaji, Norah Rami, Ellie KlibanerSchiff, Catherine McCarthy, Eamon Niknafs, and Calel Colon.

\section{References}

1. American Lung Association Metropolitan Statistical Rankings (2020) USA. http://www.stateoftheair.org/city-rankings/msas/. Accessed 1 Aug 2020.

2. BEA GDP by State (2020) USA. https://www.bea.gov/data/gdp/gdp-state. Accessed 20 Aug 2020.

3. Susan Parker Bodine (March 26, 2020) COVID-19 Implications for EPA's Enforcement and Compliance Assurance Program. In: EPA, Washington DC. (in press).

4. Business \& Human Rights Resource Center (2020)USA: Environmental Protection Agency relaxes enforcement of environmental regulations \& fines on companies amid coronavirus. https://www.businesshumanrights.org/en/usa-environmental-protection-agency-relaxes-enforcement-of-environmentalregulations-fines-on-companies-amid-coronavirus. Accessed 1 Aug 2020.

5. California Demographics: California Counties by Population (2020) USA, California. https://www.californiademographics.com/counties_by_population. Accessed 1 Aug 2020.

6. California Petroleum Statistics Weekly Fuels Watch Report (2020) USA. https://ww2.energy.ca.gov/almanac/petroleum_data/fuels_watch/index_cms.html. Accessed 1 Aug 2020.

7. Census Bureau Economic Statistics Manufacturing Snapshot (2020) USA, California. https://www.census.gov/manufacturing/mfgstat/pdfs/CAManufacturing-snapshot.pdf. Accessed 1 Aug 2020. 
8. Center For Construction Research and Training (2017) USA. https://www.cpwr.com/research/datacenter/the-construction-chart-book/chart-book-6th-edition-employment-and-income-temporary-workers-inconstruction-and-other-industries/. Accessed 20 Aug 2020.

9. DataUSA (2020) USA. https://datausa.io/profile/geo/united-states. Accessed 1 Aug 2020.

10. Coral Davenport (April 14, 2020; Updated: April 15, 2020) 'Unbelievable' Timing. In: New York Times. (in press).

11. Department for Environment, Food, and Rural Affairs (2016) Public Health. https://laqm.defra.gov.uk/publichealth/pm25.html. Accessed 1 Aug 2020.

12. EIA (2020) USA. https://www.eia.gov/energyexplained/oil-and-petroleum-products/refining-crude-oil-inputsand-outputs.php. Accessed 20 Aug 2020.

13. EIA Independent Statistics and Analysis; Petroleum and Other Liquids (2020) USA. https://www.eia.gov/dnav/pet/pet_cons_wpsup_k_w.htm. Accessed 1 Aug 2020.

14. Employment Development Department of CA (2020) USA. https://edd.ca.gov/. Accessed 1 Aug 2020.

15. EPA (March 26, 2020) EPA Announces Enforcement Discretion Policy for COVID-19 Pandemic. In: EPA News Releases. (in press)

16. EPA Outdoor Air Quality Data (2020) USA. https://www.epa.gov/outdoor-air-quality-data/download-dailydata. Accessed 1 Aug 2020.

17. EPA Regulatory and Compliance Assistance by Sector (2020) USA. https://www.epa.gov/smartsectors/regulatory-and-compliance-assistance-sector. Accessed 1 Aug 2020.

18. ESA (2020) Coronavirus Lockdown leading to drop in pollution levels across Europe In: European Space Agency. Europe (in press).

19. Furhmann, R. (2020) Okun's Law: Economics and Unemployment. In: Investopedia. USA

20. Giannakis E. et al (Dec. 17 2019). In: Environmental Sciences Europe, December Edition. Available via DIALOG. https://link.springer.com/article/10.1186/s12302-019-0275-0 of Costs and Benefits of Agricultural Ammonia Emissions. Accessed 1 Aug 2020.

21. Huang F. et al. (2015) PM2.5 Spatiotemporal Variations and the Relationship with Meteorological Factors during 2013-2014 in Beijing, China. PLOS One. doi: https://doi.org/10.1371/journal.pone.0141642.2020

22. Huiwen, N. (Sept 14, 2019) What Psi and Pm 2.5 tell you about air quality. In: The Straits Times. Singapore (In Press).

23. Lavelle et al. (2020) Environmental Laws is a Lifeline to the Oil Industry. In: inside climate news. Online (in press).

24. Machiarolla, F. to Wheeler, A. (2020) API Letter on Policy, Economics, and Public Affairs Accessed Aug 20, 2020.

25. Lauri Myllyvirta (February 09, 2020) Analysis: Coronavirus temporarily reduced China's CO2 Emissions by a Quarter. In:CarbonBrief. (in press).

26. NASA (February 25, 2020) Environmental Rollbacks. In: NASA. (in press).

27. National Environment Agency (2020) NEA Air Pollution. https://www.nea.gov.sg/our-services/pollutioncontrol/air-pollution/faqs. Accessed 2020. 
28. National Oceanic and Atmospheric Administration (2020) Clearing the Air on Weather Quality. https://www.weather.gov/wrn/summer-article-clearing-the-

air\#: :text=The\%20weather\%20can\%20have\%20a,depths\%20all\%20affect\%20pollutant\%20concentrations.. Accessed 1 Aug 2020.

29. Oil and Gas Journal (2001) Forecast and Review. In: Oil and Gas Journal Volume 118, Issue 1 Online.

30. Ramirez-Andreotta, M. (2019) Environmental Justice. Environmental and Pollution Science. doi: https://doi.org/10.1016/B978-0-12-814719-1.00031-8

31. San Francisco Bay Region Report.(2018) California's Fourth Climate Change Assessment. https://barc.ca.gov/sites/default/files/20190116-sanfranciscobayarea.pdf. Accessed 20 Aug 2020.

32. Seville L., Lehren R. (2020) Trump Administration Relaxes Regulations to Fight Coronavirus and also Loosens Environmental Restrictions. In: NBC News. USA.

33. Patrice Taddonio (April 10, 2020) Environmental Rollbacks. In: PBS Frontline. (in press).

34. Tavera Busso I, Mateos AC, Juncos LI, Canals N, Carreras HA (2018) Kidney damage induced by sub-chronic fine particulate matter exposure. Environ Int 121:635-642.

35. United States Dept of Labor Unemployment Database (2020) USA. https://oui.doleta.gov/unemploy/claims.asp. Accessed 1 Aug 2020.

36. Wu, X. et al. (2020) COVID-19 PM 2.5. https://projects.iq.harvard.edu/covid-pm. Accessed 1 Aug 2020.

37. Zhang N. et al. (2018) Quantitative analysis between pm 2.5 concentration and factors on industry, energy, agriculture, and transportation. Scientific Reports natureresearch. doi:10.1038/s41598-018-27771-w.

38. Zhou T, Hu Y, Wang Y, Sun C, Zhong Y, Liao J, Wang G (2019) Fine particulate matter (PM2.5) aggravates apoptosis of cigarette-inflamed bronchial epithelium in vivo and vitro. Environ Pollut 248:1-9.

\section{Figures}

\section{Fig. 1}
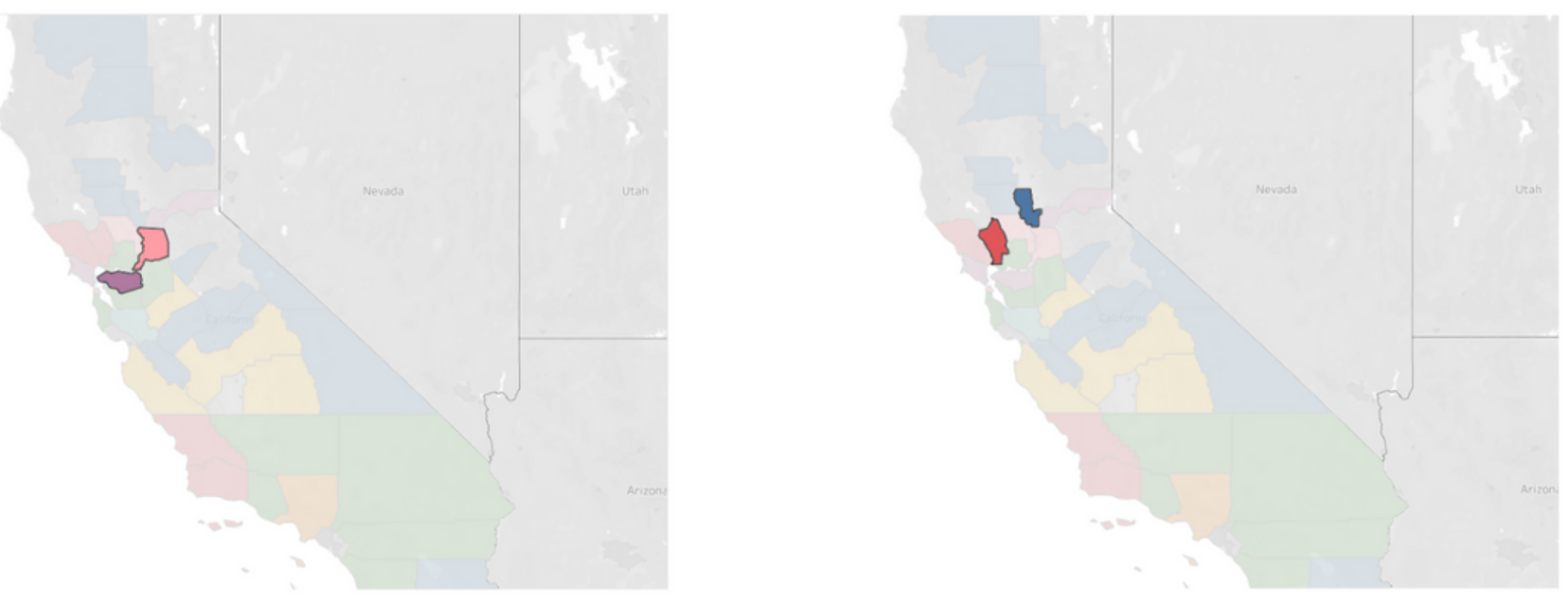

\section{Figure 1}

Geographic locations of Contra Costa and Sacramento (left) and Napa and Sutter (right) 
Fig. 2

$\mathbf{a}$

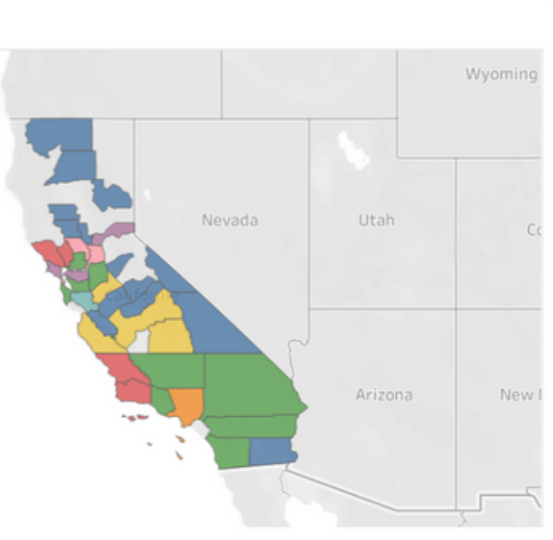

c

County $\bar{F}$

Contra Cost.

$$
\text { Napa }
$$

Sutter
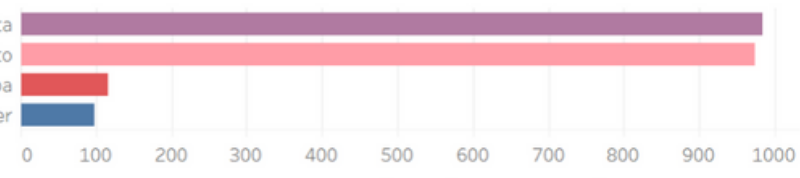

Population Density (people/square kilometer)
Manufacturing Sector

Null

$\square$ Apparel manufacturing

$\square$ Beverage and tobacco product manufacturing

$\square$ computer and electronic product manufacturing

$\square$ Fabricated metal product manufacturing

$\square$ Food manufacturing

$\square$ Miscellaneous manufacturing

$\square$ Printing and related support activities

b

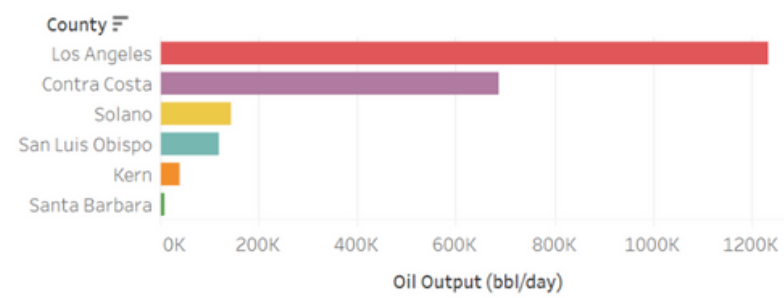

d

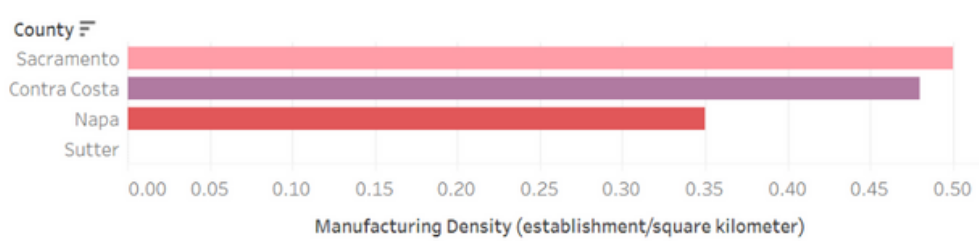

\section{Figure 2}

Economic overview of select California counties. Using data from the United States 2010 Census Bureau and journal Oil, we graphed a. main manufacturing sectors for 30 Californian counties, b. output of major Californian oil refineries, c. population density, and d. manufacturing density

\section{Fig. 3}
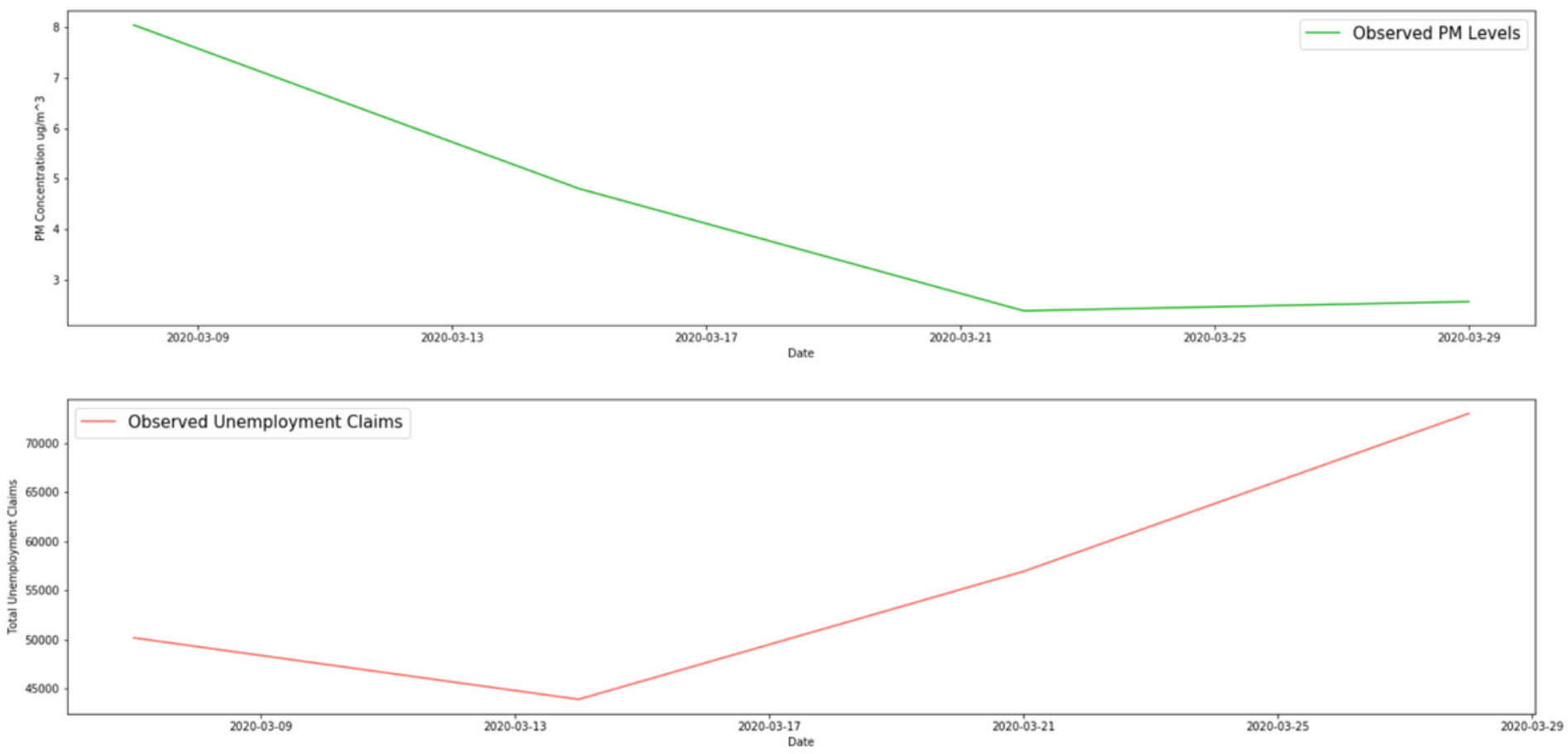

Figure 3

Page $19 / 23$ 
Comparison of weekly PM2.5 levels (top) and local unemployment levels (bottom) in Fresno, California in March 2020

\section{Fig. 4}
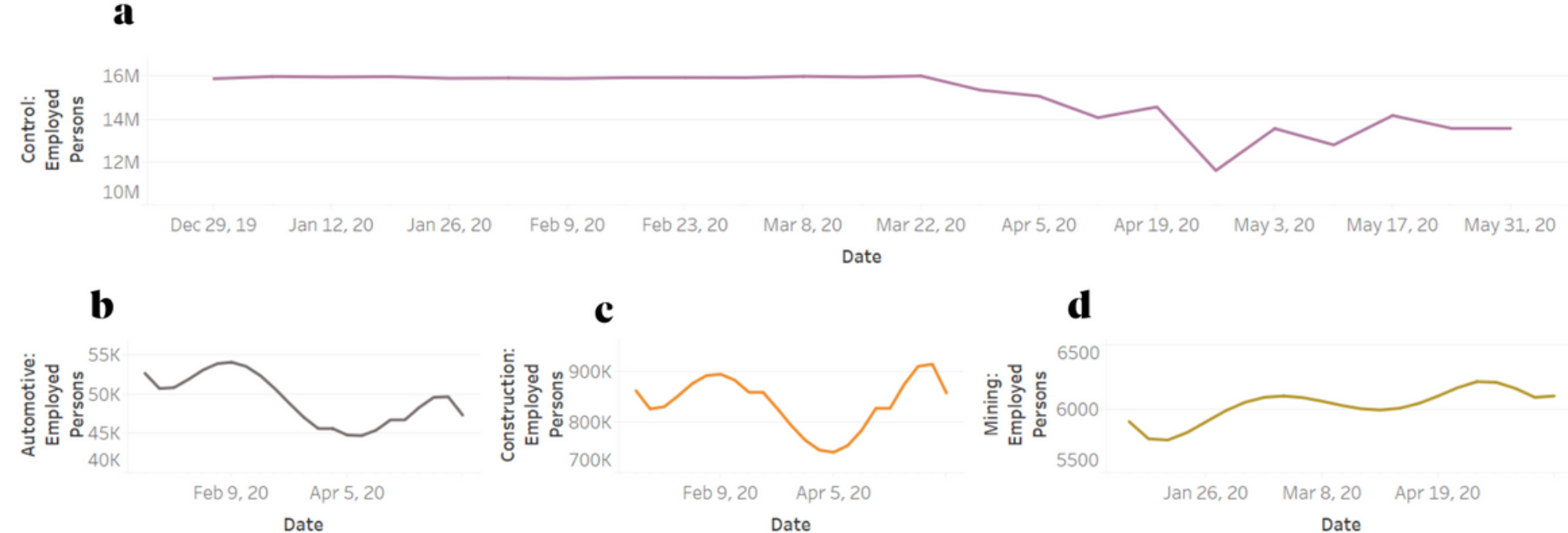

c Date
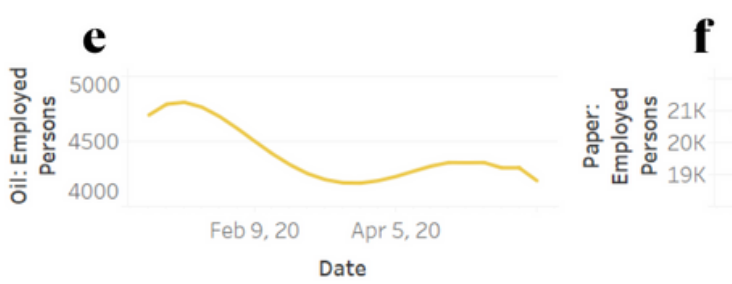

f
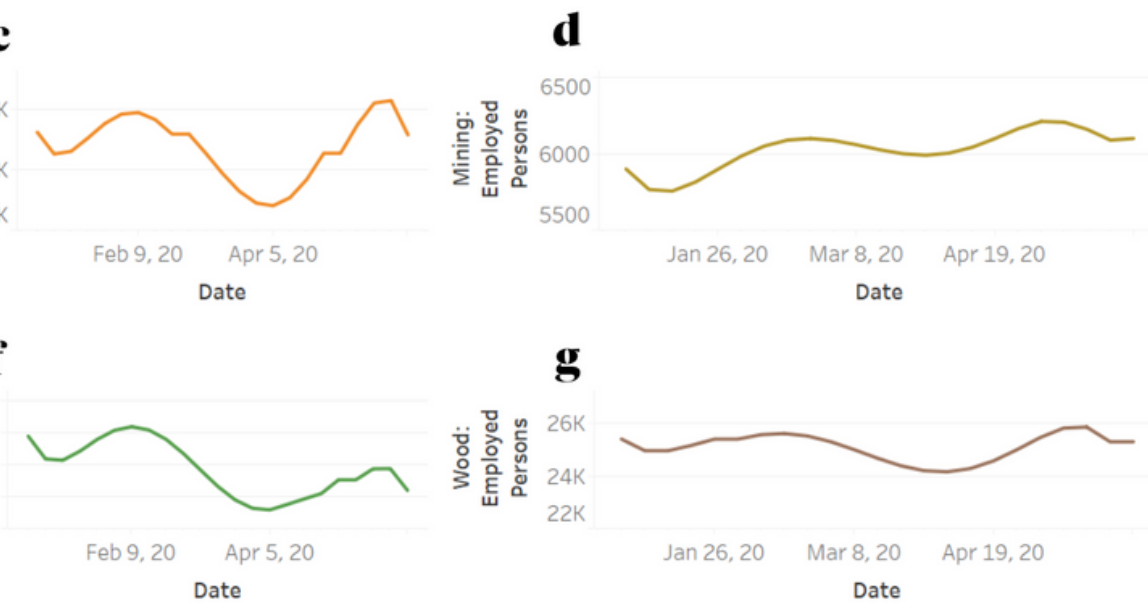

\section{Figure 4}

Total employed persons for treatment and control industries. Using an algorithm to predict an industry's total employment, graphs for total employed persons for a. all control, b. automotive, c. construction, d. mining, e. oil, f. paper, and g. wood industries were created 
Fig. 5

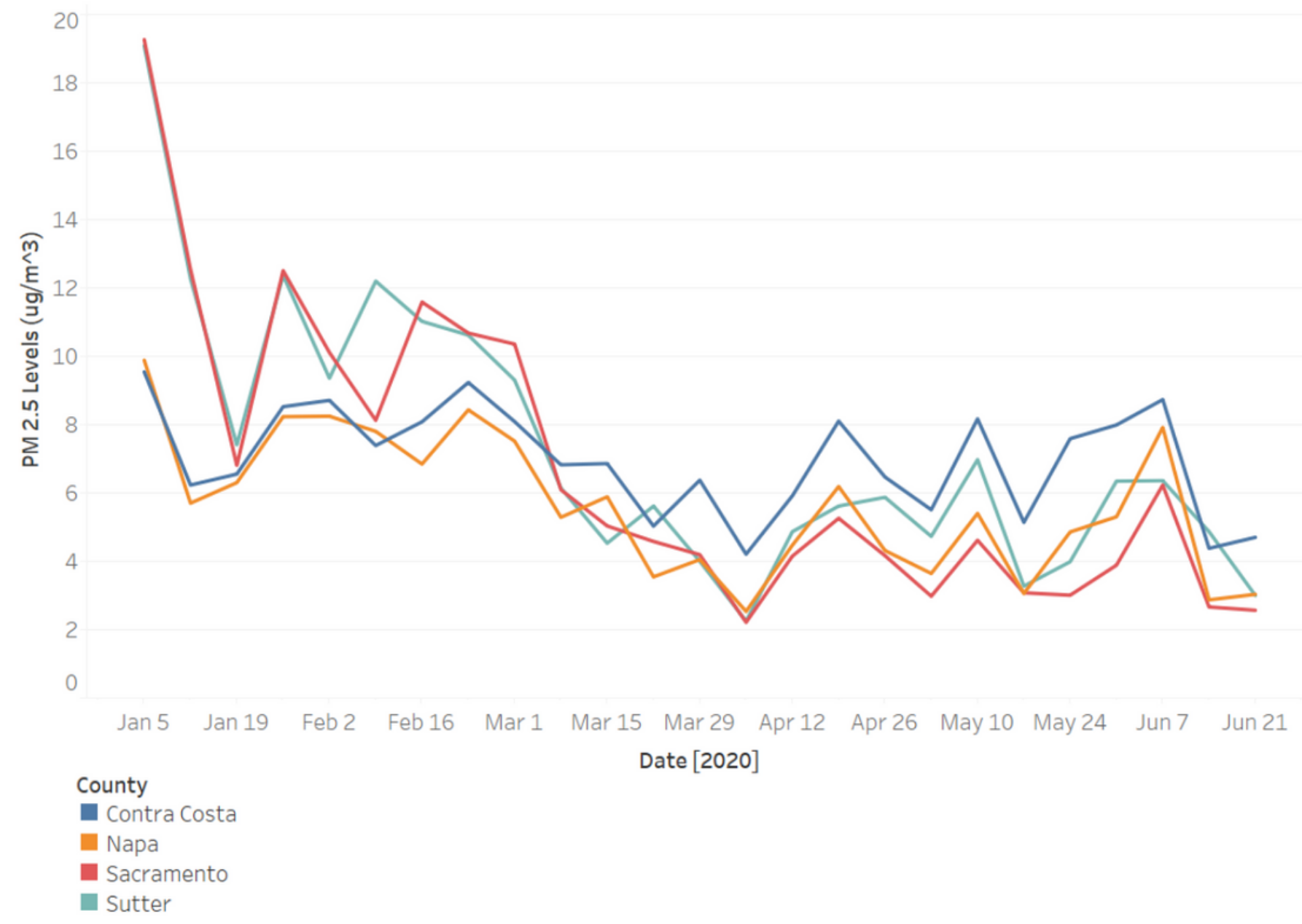

Figure 5

Weekly PM2.5 Levels Across all 4 counties from January 2020 to June 2020 


\section{Fig. 6}

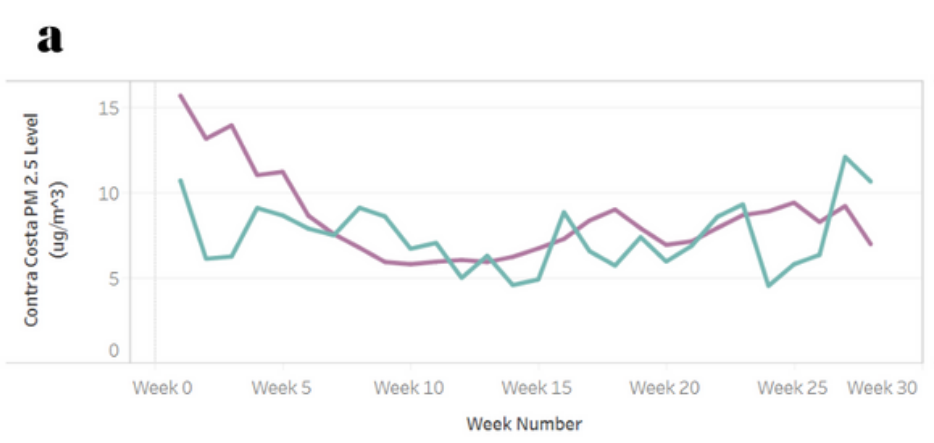

\section{b}
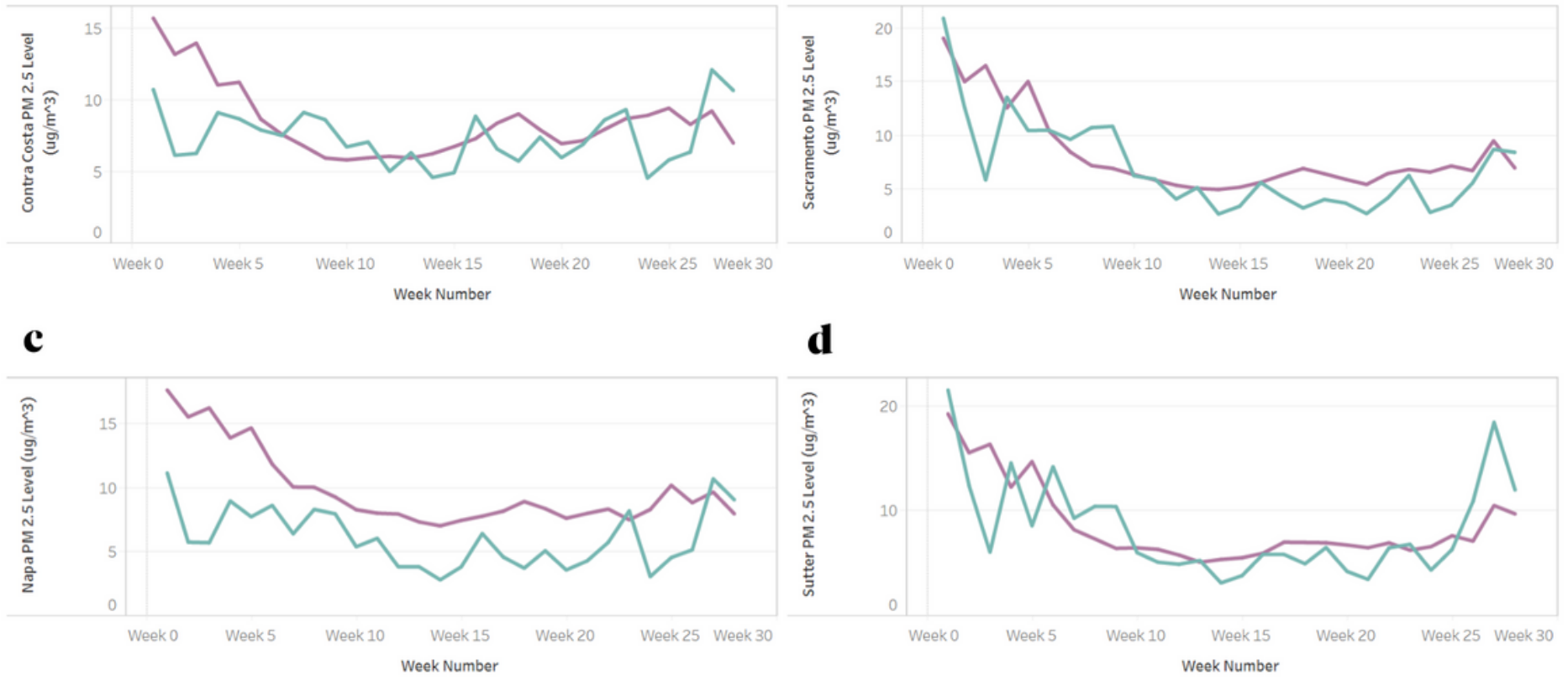

\section{d}

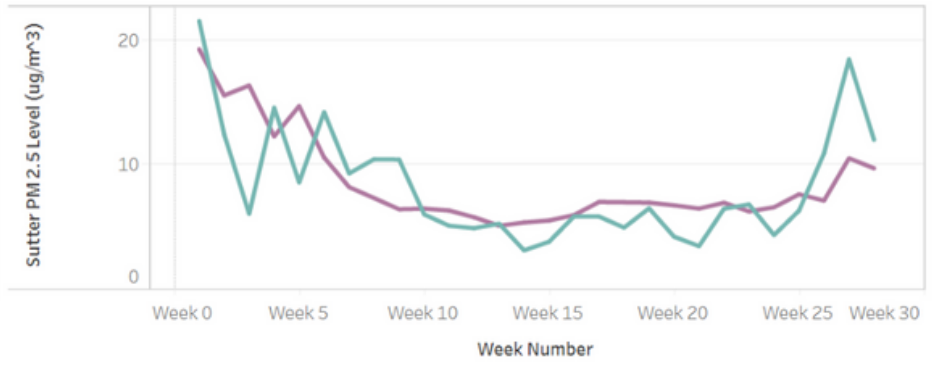

2009.2019 Weekly Averages

2020 Weekly Averages

\section{Figure 6}

Difference between average 2009-2019 PM2.5 levels and 2020 PM2.5 levels for a Contra Costa, b Sacramento, c Napa, and d Sutter

\section{Supplementary Files}

This is a list of supplementary files associated with this preprint. Click to download.

- California.csv

- California2009.csv

- California2010.csv

- California2011.csv

- California2012.csv

- California2013.csv

- California2014.csv

- California2015.csv

- California2016.csv

- California2017.csv

- California2018.csv

- California2019.csv 
- CaliforniaEmploymentIndustry.csv

- CaliforniaEmploymentIndustryControl.csv

- CaliforniaUnemployment.csv

- ContraSacraNapaSutt20092020.csv

- CorrelValues.csv

- JanJunUpdated.csv

- RawFresnoUnemployment.csv

- ResearchIntoCaliforniaVer2.csv

- Thumbs.db

- updatedAutoData.csv

- updatedConstructionData.csv

- updatedMiningData.csv

- updatedOilData.csv

- updatedPaperData.csv

- updatedWoodManufacturing.csv 